\title{
1. Sectoral systems of innovation and production in developing countries: an introduction
}

\section{Franco Malerba and Sunil Mani}

\section{THE REASON FOR THIS BOOK}

Sectoral systems of innovation and production have been a growing new area of research in industrial economics and the economics of innovation. This growth is due to two basic reasons. First, a sectoral system approach considers a wide range of factors that affect innovation and production in a sector. It places firms and the related capabilities and learning processes as the major drivers of innovation and production. At the same time it pays central attention to other relevant factors that affect innovation and production in a sector: the variety of actors, networks, demand and institutions. In particular, a sectoral system approach examines innovation as the result of both firms' specific variables (such as firms' learning and capabilities, R\&D and production investments, strategies and organizational structure) and the type of knowledge and technologies that characterize a sector, the links and interdependencies with other related sectors, the role of actors (such as competitors, suppliers, users, universities, financial organizations, public agencies and the government), the characteristics of demand and the type of institutions (such as standards, regulations and norms). A second reason is that a sectoral system approach has a dynamic perspective and takes a process view. Thus it pays a lot of attention to exchange, competition, and cooperation in a coevolutionary setting. A major conclusion of the sectoral system approach is that all these factors and processes often differ from sector to sector and consequently have to be understood in their effects on innovation, diffusion and production. It must be noted that the dimensions of sectoral systems are not necessarily national: they may be also local or global.

Therefore the approach calls for a deep understanding of the interplay between national systems and sectoral systems.

A sectoral system approach for the study of innovation and production 
in sectors, however, is not a straitjacket, but a broad, flexible and adaptable tool. It points to some key variables and fundamental relationships. Only the goals of the analysis will decide which levels of aggregation should be used, depending on the purpose of the analysis. This approach enables quantitative and qualitative comparative analyses across industries, countries and regions because it allows a focusing on the same set of variables. It also provides a framework for policy.

Up to now, the work on sectoral systems has concerned mainly developed countries (see, for example, Malerba, 2004).

There has been, however, an emerging interest in analyses of sectoral systems of innovation and production in developing countries. There are several reasons for that. Innovation and diffusion have become relevant in most developing countries. Processes of fast growth have been associated with some sectors such as automobiles, electronics and software as well as with the transformation of traditional sectors such as agriculture or food. But the differences across all these sectors in terms of structure and dynamics have been so great that a full understanding of these differences is necessary if innovation is to be encouraged and growth sustained.

Therefore this book aims to answer questions such as the following: What are the main features of sectoral systems of innovation and production in developing countries? How do they change and evolve? What are the main policy lessons that one can draw from the analysis of sectoral systems?

This book aims at answering these questions by examining a wide range of sectoral systems, from traditional to high technology ones. It does it for a variety of countries. The book originates from the contributions initially presented at the Globelics India Conference at Trivandrum in 2006. After the conferences the papers were completely revised and rewritten for this book.

The book is composed of three parts. After an introduction to the volume by Franco Malerba and Sunil Mani, Part II examines the main actors and structure of some key sectoral systems in developing countries. Sunil Mani (Chapter 2) shows that in the same country (India) two different sectors may have a quite different performance because of the features of the specific sectoral systems. Then the book moves to examine key actors and features of sectoral systems in various sectors: Fernando Perini (Chapter 3) discusses networks and knowledge flows in ICT in Brazil; Hannes Toivanen and Maria Barbosa Lima Toivanen (Chapter 4) emphasize the role of private sector firms in the Brazilian pulp and paper industry; Marjolein Caniëls, Effie Kesidou and Henny Romijn (Chapter 5) point to the role of skills, entrepreneurship and clusters in software in Uruguay; Rosane Argou Marques and L. Guilherme de Oliveira (Chapter 
6) discuss the geographical boundaries of the aeronautical sector in Brazil. Part III of the book examines key aspects of the dynamics and evolution of sectoral systems. Patarapong Intarakumnerd and Mai Fujita (Chapter 7) point out that the same sector may evolve quite differently and examine the case of the motorcycle in Thailand and Vietnam; Michiko Iizuka (Chapter 8) illustrates how 'low tech' sectors can be highly dynamic in their path to development and examine salmon farming in Chile; Yoon-Zi Kim and Keun Lee (Chapter 9) discuss the role of interdependencies and demand in a key capital good industry such as machine tools in Korea; Ting-Lin Lee (Chapter 10) identifies the key role of two public actors in the evolution of the ICT industry in Taiwan, and finally Janske van Eijck and Henny Romijn (Chapter 11) examine the creation of a new sectoral system in a rural area in Tanzania.

This introductory chapter is organized in the following way. Section 2 contains a general discussion of sectoral systems. In section 3 the major themes and points of the book are presented. Finally section 4 draws some conclusions emerging from the findings of this book.

\section{SECTORAL SYSTEMS: AN INTRODUCTION}

A sectoral system framework focuses on the nature, structure, organization and dynamics of innovation and production in sectors. A sector can be broadly defined as a set of activities that are unified by some linked product groups for a given or emerging demand and that share some common knowledge. Firms in a sector have some commonalities and at the same time are heterogeneous in terms of learning processes and capabilities. A sectoral system has the following elements: (a) firms in the sector; (b) other actors (in addition to firms); (c) networks; (d) demand; (e) institutions; (f) knowledge; and (g) the basic processes of interaction, variety generation, selection and coevolution. (For a more general discussion see Malerba, 2002 and 2004.)

The notion of sectoral systems has the evolutionary theory and the innovation system approach as building blocks. Evolutionary theory places a key emphasis on dynamics, innovation processes and economic transformation. Learning and knowledge are key elements in the change of the economic system. "Boundedly rational" agents act, learn and search in uncertain and changing environments. Agents know how to do things in different ways. Thus learning, knowledge and behaviour entail agents' heterogeneity in experience and organization; and different competences affect persistent differential performance. In addition, evolutionary theory places emphasis on cognitive aspects such as beliefs, 
objectives and expectations, which are in turn affected by previous learning and experience and by the environment in which agents act. A central place in the evolutionary approach is occupied by the processes of variety creation (in technologies, products, firms and organizations), replication (which generates inertia and continuity in the system) and selection (which reduces variety in the economic system and discourages the inefficient or ineffective utilization of resources). Finally, aggregate phenomena are emergent properties of far-from-equilibrium interactions and have a metastable nature (Nelson, 1995; Dosi, 1997; Metcalfe, 1998). For evolutionary theory the environment and conditions in which agents operate may drastically differ. Evolutionary theory stresses major sectoral differences in opportunities related to science and technologies. The same holds for the knowledge base underpinning innovative activities, as well as for the institutional context. Thus the learning, behaviour and capabilities of agents are constrained and "bounded" by the technology, knowledge base and institutional context. Heterogeneous firms facing similar technologies, searching around similar knowledge bases, undertaking similar production activities, and "embedded" in the same institutional setting share some common behavioural and organizational traits and develop a similar range of learning patterns. The notion of the sectoral system of innovation and production is also linked to the innovation system literature (Edquist, 1997) in that it focuses on learning and interaction among agents. It complements concepts such as national systems of innovation, which are delimited by national boundaries and focused on the role of non-firm organizations and institutions (Freeman, 1987; Lundvall, 1993; Nelson, 1993), regionalllocal innovation systems, in which the boundary is the region (Cooke et al., 1997), technological systems, in which the focus is on technologies and not on sectors (Hughes, 1987; Callon, 1992; Carlsson and Stankiewitz, 1995), and distributed innovation systems, in which the focus is on specific innovations (Andersen et al., 2002).

As an introduction, let's briefly discuss the main elements of a sectoral system in a general way:

a. Firms in the sector. Firms are the key actors in innovation and production in a sectoral system. They are characterized by specific learning processes, capabilites and organizational structures, as well as by beliefs, expectations and goals (Nelson and Winter, 1982; Teece and Pisano, 1994; Dosi et al., 2000).

b. Other actors. In addition to firms, a sector is composed of other agents, which are organizations or individuals. Organizations may be suppliers, users, universities, financial institutions, government agencies, trade unions or technical associations. Individuals may be 
consumers, entrepreneurs or scientists. These agents are also characterized by specific learning processes, competencies, beliefs, objectives, organizational structures and behaviours. Agents interact through processes of communication, exchange, cooperation, competition and command.

c. Networks. Within any sectoral system, firms are connected in various ways through market and non-market relationships. Traditional analyses of industrial organizations have examined agents as involved in processes of exchange, competition and command (such as vertical integration). In more recent analyses, processes of formal cooperation or informal interaction among firms or among firms and non-firm organizations have been examined in depth (as one may see from the literature on tacit or explicit collusion, hybrid governance forms, or formal R\&D cooperation). This literature has analysed firms with certain market power, suppliers, users facing opportunistic behaviour or asset specificities in transaction, or firms with similar knowledge having appropriability and indivisibility problems in R\&D. The evolutionary approach has emphasized that in uncertain and changing environments formal as well as informal networks emerge not because agents are similar but because they are different. Thus, networks integrate complementarities in knowledge, capabilities and specialization. Relationships between firms and non-firm organizations (such as universities and public research centres) have been a source of innovation and change in several sectoral systems: pharmaceuticals and biotechnology, information technology, and telecommunications (Nelson and Rosenberg, 1993). The types and structures of relationships and networks differ greatly from sectoral system to sectoral system, as a consequence of the features of the knowledge base, the relevant learning processes, the basic technologies, the characteristics of demand, the key links and the dynamic complementarities.

d. Demand. In a sectoral system, demand may be domestic or international. Demand is not seen as an aggregate set of similar buyers or of atomistic undifferentiated customers, but as composed of heterogeneous agents who interact in various ways with producers. In this way, demand becomes composed of individual consumers, firms and public agencies, which could be part of different countries and national innovation systems, characterized by different size, knowledge, learning processes and competencies, and affected by different social factors and institutions.

e. Institutions. Agents' cognition, actions and interactions are shaped by institutions, which include norms, routines, common habits, established practices, rules, laws, standards and so on. Institutions may 
range from ones that bind or impose enforcements on agents to ones that are created by the interaction among agents (such as contracts), from more binding to less binding, and from formal to informal (such as patent laws or specific regulations as against traditions and conventions). A lot of institutions are national (such as the patent system), while others are specific to sectors (such as sectoral labour markets or sector-specific financial institutions). In all sectoral systems, institutions play a major role in affecting the rate of technological change, the organization of innovative activity, and performance. They may emerge either as a result of deliberate, planned decisions by firms or other organizations, or as the unpredicted consequence of agents' interaction. Some institutions are sectoral (i.e. specific to a sector), while others are national, and others may be international.

The relationship between national institutions and sectoral systems is quite important in most sectors. National institutions have different effects on sectors. For example, the patent system, property rights or antitrust regulations have different effects as a consequence of the different features of the sectoral systems, as surveys and empirical analyses have shown (see, for example, Levin et al., 1987). However, the same institution may take on different features in different countries, and thus may affect the same sectoral system differently. Often, the characteristics of national institutions favour specific sectors that fit better the specificities of the national institutions. Thus, in certain cases, some sectoral systems become predominant in a country because the existing institutions of that country provide an environment more suitable for certain types of sectors and not for others. In other cases, national institutions may constrain the development or innovation in specific sectors, or mismatches between national and sectoral institutions and agents may take place. The examples of the different types of interaction between national institutions and sectoral evolution in various advanced countries in Dosi and Malerba (1996) are cases in point. The relationship between national institutions and sectoral systems is not always one-way, as it is in the case of the effects of national institutions on sectoral variables. Sometimes, the direction is reversed, and goes from the sectoral to the national level. In fact, it may occur that the institutions of a sector, which are extremely important for a country in terms of employment, competitiveness or strategic relevance, end up emerging as national, thus becoming relevant for other sectors. But, in the process of becoming national, they may change some of their original distinctive features.

f. The knowledge base. Any sector is characterized by a specific knowledge base, technologies and inputs. Knowledge plays a central role in 
innovation and affects the types of learning and capabilities of firms. In a dynamic way, the focus on knowledge and the technological domain places at the centre of the analysis the issue of sectoral boundaries, which usually are not fixed, but change over time. Knowledge is highly idiosyncratic at the firm level, does not diffuse automatically and freely among firms, and has to be absorbed by firms through their differential abilities accumulated over time. The evolutionary literature has proposed that sectors and technologies differ greatly in terms of the knowledge base and learning processes related to innovation. Knowledge differs across sectors in terms of domains. One knowledge domain refers to the specific scientific and technological fields at the base of innovative activities in a sector (Dosi, 1988; Nelson and Rosenberg, 1993), while another regards applications, users, and the demand for sectoral products. Recently, a major discontinuity has taken place in the processes of knowledge accumulation and distribution with the emergence of the knowledge-based economy, which has redefined existing sectoral boundaries, affected relationships among actors, reshaped the innovation process, and modified the links among sectors.

What do we know about the main dimensions of knowledge? First, knowledge may have different degrees of accessibility (Malerba and Orsenigo, 2000), that is opportunities of gaining knowledge external to firms, which in turn may be internal or external to the sector. In both cases, greater accessibility of knowledge may decrease industrial concentration. Greater accessibility internal to the sector implies lower appropriability: competitors may gain knowledge about new products and processes and, if competent, imitate those new products and processes. Accessibility of knowledge that is external to the sector may be related to the levels and sources of scientific and technological opportunities. Here, the external environment may affect firms through human capital with a certain level and type of knowledge or through scientific and technological knowledge developed in firms or non-firm organizations, such as universities or research laboratories. Knowledge may be more or less cumulative, that is the degree by which the generation of new knowledge builds upon current knowledge. One can identify three different sources of cumulativeness. The first source is cognitive. The learning processes and past knowledge constrain current research, but also generate new questions and new knowledge. The second source is related to the firm and to its organizational capabilities. Organizational capabilities are firm-specific and generate knowledge which is highly path-dependent. They implicitly define what a firm learns and what it can hope to achieve in the future. 
A third source is the feedback from the market, such as in the "success-breeds-success" process. Innovative success yields profits that can be reinvested in $\mathrm{R} \& \mathrm{D}$, thereby increasing the probability of innovating again. In the case of knowledge spillovers within an industry, however, it is also possible to observe cumulativeness at the sectoral level. Cumulativeness may also be present at the local level. In this case, high cumulativeness within specific locations is more likely to be associated with low appropriability conditions and spatially localized knowledge spillovers.

The sources of technological opportunities markedly differ among sectors. As Freeman (1982) and Rosenberg (1982), among others, have shown, in some sectors opportunity conditions are related to major scientific breakthroughs in universities. In other sectors, opportunities to innovate may often come from advancements in R\&D, equipment and instrumentation. In still other sectors, external sources of knowledge in terms of suppliers or users may play a crucial role. Not all external knowledge may be easily used and transformed into new artefacts. If external knowledge is easily accessible, transformable into new artefacts and exposed to a lot of actors (such as customers or suppliers), then innovative entry may take place. If advanced integration capabilities are necessary (Cohen and Levinthal, 1989), the industry may be concentrated and formed by large, established firms. Knowledge affects also the types of learning processes and the relevant capabilities that firms have in order to be competitive and innovate. In general, the features and sources of knowledge affect the rate and direction of technological change, the organization of innovative and production activities, and the factors at the base of firms' successful performance.

The boundaries of sectoral systems are affected by the knowledge base and technologies, as well as by the type of demand and links and complementarities among artefacts and activities. These links and complementarities are, first of all, of the static type, as are input-output links. Then there are dynamic complementarities, which take into account interdependencies and feedbacks, both at the demand and at the production levels. Dynamic complementarities among artefacts and activities are major sources of transformation and growth of sectoral systems, and may set in motion virtuous cycles of innovation and change. This could be related to the concept of filière and the notion of development blocks (Dahmen, 1989). Links and complementarities change over time and greatly affect a wide variety of variables of a sectoral system: firms' strategies, organization and performance, the rate and direction of technological change, the type of competition and the 
networks among agents. Thus the boundaries of sectoral systems may change more or less rapidly over time, as a consequence of dynamic processes related to the transformation of knowledge, the evolution and convergence in demand, changes in competition and learning by firms.

g. The main processes and coevolution. The analysis of sectoral systems requires also a careful understanding of the processes of interaction, cooperation and competition. In a sectoral system framework, innovation is considered to be a process that involves systematic interactions among a wide variety of actors for the generation and exchange of knowledge relevant to innovation and its commercialization. Interactions include market and non-market relations that are broader than the market for technological licensing and knowledge, inter-firm alliances, and formal networks of firms.

Over time, a sectoral system undergoes processes of change and transformation through the coevolution of its various elements. This process involves technology, demand, knowledge base, learning processes, firms, non-firm organizations and institutions. Nelson (1994) and Metcalfe (1998) have discussed these processes at the general level by focusing on the interaction between technology, industrial structure, institutions and demand. The claim here is that these processes are sector-specific. For example, just looking at three elements such as technology, demand and firms, in sectors characterized by a system product and consumers with a rather homogeneous demand, coevolution leads to the emergence of a dominant design and industrial concentration (Klepper, 1996). However, in sectors with a heterogeneous demand, specialized products and a more fragmented market structure may emerge. Often coevolution is related to path-dependent processes (David, 1985; Arthur, 1989). Here local learning, interactions among agents and networks may generate increasing returns and irreversibilities that may lock sectoral systems into inferior technologies.

h. Three last introductory points. Three last points on sectoral systems have to be made here by way of introduction. First, what are the main differences between a sectoral innovation system and a national innovation system perspective? While national innovation systems take innovation systems as delimited more or less clearly by national boundaries, a sectoral system approach would claim that the boundaries of the innovations process in sectors have local, national and/ or global dimensions. Often these three different dimensions coexist in a sector. In addition, national innovation systems result from the different composition of sectors, some of which are so important that they drive the growth of the national economy. For example, Japanese 
growth in the 1970s and 1980s was driven by specific sectors, which were different from the sectors behind the American "resurgence" during the 1990s. As has been pointed out previously, an understanding of the key driving sectors of an economy with their specificities greatly helps in understanding national growth and national patterns of innovative activities.

Second, a relevant remark refers to the aggregation issue regarding products, agents or functions. For example, sectoral systems may be examined broadly or narrowly (for example, in terms of a small set of product groups). A broad definition allows us to capture all the interdependencies and linkages in the transformation of sectors, while a narrow definition identifies more clearly specific relationships. Of course, within broad sectoral systems, different innovation systems related to different product groups may coexist. The choice of the level of aggregation depends on the goal of the analysis.

Third, a sectoral system perspective should not be seen as a rigid and closed framework, but as a broad, open and flexible framework, able to encompass different elements and variables, according to the focus of the analysis. However, the driving elements of the analysis still have to be knowledge, capabilities, variety of actors, interactions and institutions.

\section{THE MAJOR THEMES AND POINTS OF THIS BOOK}

The chapters in this book identify several relevant aspects of sectoral systems in developing countries that are key for understanding innovation, competitiveness and growth in these countries. They could be grouped in two major parts, which constitute the two parts of this book.

\subsection{Understanding the Key Actors and the Main Characteristics of Sectoral Systems and their Effects on Innovation and Developments (PART II)}

Some major points emerge from the chapters included in Part II:

- In the same country two technology-intensive sectors may end up having a quite different innovative and competitive performance owing to the different structure of their sectoral systems. The case of pharmaceuticals and telecommunication equipment in India.

This first point is examined by Sunil Mani in "Why is the Indian pharmaceutical industry more innovative than its telecom- 
munications equipment industry?" Mani starts from the remark that in India two sectors which are highly technology-intensive - such as pharmaceuticals and telecommunications equipment have had quite different innovative and competitive performance owing to the different structure of the two sectoral systems. In both pharmaceuticals and telecom equipment the Indian government intervened early on through essentially the creation of important supporting institutions and instruments. But the innovative performance of both industries has been different: the drug industry has become self-sufficient, has emerged as a net exporter and has a strong patenting record abroad, while the telecommunications industry has increasingly become dependent on MNCs and imports, and the industry does not have many patents to boast of. The differences in outcomes is explained by the differences in the sectoral systems of innovation. In pharmaceuticals, the innovation system of the industry has three strong pillars: private sector enterprises which have invested in innovation, a very proactive government policy regime especially with respect to intellectual property rights, and strong government research institutes. The TRIPS compliance of the intellectual property rights regime making it mandatory for pharmaceutical products to be patented has not reduced the innovation capability of the industry, although it has not made it work on $\mathrm{R} \& \mathrm{D}$ projects that may lead to the discovery of drugs for neglected diseases of the developing world. However, the two main components of the innovation system, namely the enterprises and the government research institutes, do not appear to have all the requisite capabilities to bring a new drug to the market. This is an area where public policy support is still required. In telecommunication equipment, on the contrary, India followed a very rigid policy of indigenous development of domestic technologies by establishing a stand-alone public laboratory that developed state-of-the-art switching technologies. These were then transferred to manufacturing enterprises in both public and private sectors. The domestic enterprises themselves did not have any in-house R\&D capability. As a consequence the enterprises were completely dependent on the public laboratory for research. Most of the enterprises constituting the telecom equipment sectoral systems have become mere traders, distributing products manufactured elsewhere. Thus the country, despite possessing good-quality human resources, was unable to keep pace with changes in the technology frontier, and the equipment industry has now become essentially dominated by affiliates of MNCs and by imports. 
- The knowledge base of a sector greatly affects the organization of innovative activity and the type of networks. ICT in Brazil.

Fernando Perini, in "From innovation projects to knowledge networks: knowledge as contingency in the sectoral organization of innovation", examines the relationship between the sectoral knowledge base and the organization of innovative activity in ICT in Brazil. In particular, the type of knowledge base affects the balance between hierarchies and market, the type of governance mechanisms and the inter-organizational channels of knowledge flows. Looking at ICT, strong tie networks are formed in software and middleware, weak tie networks are formed in training, technological services and research, and very limited networks are present in semiconductors, production processes and hardware. In general, early initiatives in product development are associated with higher internalization levels. Different types of organizations did different things. Domestic companies remained focused in hardware and middleware (close to manufacturing activities), while multinational companies connected to private research institutes were important in the emerging software technology. Public research centres and educational institutions became central in training and research activities. The different roles of these organizations reinforce the importance of diversity in governance structures and the different mechanisms for interaction between public and private as well as domestic and multinational stakeholders inside the sectoral systems. The low correlation between the networks in different activities, however, shows that different types of knowledge tended to flow in distinct communities of practice. There were, however, some connections between the types of activities. In particular, three distinct strong connections emerged between different communities: the first took place between production process and laboratorial infrastructure/equipments on one side and training on the other, the second between research and technological services, and the third between product development activities in middleware and software.

- Private sector enterprises are key actors in a sectoral system of innovation. The pulp and paper industry in Brazil.

This is the message that one gets from the chapter by Hannes Toivanen and Maria Barbosa Lima-Toivanen, 'Learning, innovation and public policy: the emergence of the Brazilian pulp and paper industry'. Brazil occupies an important position among the major world producers of pulp and paper: in 2007 it was the world's sixth largest pulp producer and the eleventh largest paper producer. In 2006, the industry's total exports were about US\$4.7 billion. 
It is generally considered to be a successful case. One of the most important agents in the sectoral system is the private sector firms. At present there are 220 companies spread throughout 450 municipalities and located in 17 states and five regions. Public policies did not hamper firms' competitiveness in the market. Rather, entrepreneurs and business managers enjoyed, and operated under, healthy, internationally competitive incentives for the creation and adoption of scientific, technological and business innovations.

- Advanced human capital, vibrant entrepreneurship and intense spinoffs are at the heart of the clustering of innovative activities in skillintensive sectors. Software in Uruguay.

Marjolein C.J. Caniëls, Effie Kesidou and Henny Romijn, in 'The software sector in Uruguay: a sectoral systems of innovation perspective', examine the key role of local skills and clustering of innovative activity in a sector such as software in Uruguay. The sector has undergone a high growth since its inception in the early 1990s. Important factors leading to the emergence of the sector have been favourable demand conditions in Latin America, and the presence of skilled manpower, which can be related to an emphasis on education by the Uruguayan state. The sector is highly clustered geographically, and consists predominantly of a multitude of small and medium-sized firms, indicating that knowledge in the software sector is cumulative mainly at the local cluster level. The sector grew by fulfilling increasing local demand for enterprise resource planning products for small and medium-sized firms, which were overlooked by multinational companies. Uruguayan software companies combined advanced technological knowledge with knowledge about specific markets and applications such as banking, finance, education, health and construction. Successful products were addressed to specific applications or specific customers and incorporated new technological developments. The sectoral system has developed owing to the presence of skilled workers with a good level of education and has grown over time through intense entrepreneurship, spin-offs and labour mobility. Firms learn through internal efforts (R\&D) but also access external knowledge and information through networking. In this sectoral system no major role of policy has been present except the one concerning human capital formation and the creation of a good level of general infrastructure. Direct promotion of the sector through public policies and institutional support has not played a major role in the emergence of the sector.

- Sectoral systems of innovation need not be confined to national borders, but can in fact be global, and therefore the interactions they 
may have with local actors may diminish over time. The aeronautical sector in Brazil.

Rosane Argou Marques and L. Guilherme de Oliveira in their chapter on 'Sectoral system of innovation in Brazil: reflections about the accumulation of technological capabilities in the aeronautical sector (1990-2000)' advance the point that a sectoral system of innovation has boundaries extending beyond the region and the nation and in fact it very often extends abroad to foreign locations. This is demonstrated with an examination of the Brazilian aircraft manufacturing sector. This sector is dominated by the Brazilian aircraft manufacturer Embraer. The firm was established in 1969 by the Brazilian military government, and it was a state-owned undertaking until 1994 when it was privatized. Although it is successful in achieving international competitiveness in its specific market segment for regional jets, Brazil has not been able to consolidate the supply chain of Embraer within its national borders. There are now only a few Brazilian firms supplying Embraer and some of the foreign first-tier suppliers of Embraer. In fact, the import content increased from about 68 per cent in the 1980s to approximately 95 per cent in the 1990s. Therefore, there is a question about how the local Brazilian suppliers are maintaining themselves in the competitive supply chain of Embraer. The findings of the present analysis show that the local suppliers are improving their innovative capabilities in two directions: by strengthening their basic technological capability regarding production processes and, in a few cases, by upgrading to intermediate and advanced levels of innovative capability. The relationship with Embraer, foreign buyers and Brazilian research institutions are the main sources of knowledge for the technological learning experienced by these Brazilian suppliers that are "surviving" in the supply chain of Embraer.

\subsection{The Dynamics and Evolution of Sectoral Systems (PART II)}

In this part one can also identify some major points:

- The same sectors can evolve differently when they are facing similar threats and opportunities. The motorcycle industry in Thailand and Vietnam.

Patarapong Intarakumnerd and Mai Fujita in their chapter on 'China's threat and opportunity for the Thai and Vietnamese motorcycle industries: a sectoral innovation system analysis' trace the evolution of the sectoral system of innovation of the motorcycle 
industry in both Thailand and Vietnam. The findings illustrate that different sectoral systems of innovation and production evolve differently. The direction and the pace of evolution depend very much on existing absorptive capabilities of agents, strength of their linkages and their process of collective learning to withstand the threats and exploit the opportunities. The industry in both the countries had to face strong import competition from China. The type of response of the sectoral system depended very much on the nature of the economic agents. To illustrate, Thailand can withstand the threats and exploit the opportunities better than Vietnam because, despite still being rather weak and fragmented, its motorcycle sectoral system of innovation and production has relatively more capable agents (i.e. longer-present and more technologically sophisticated TNCs, local champions who are own-brand manufacturers), a government with more vivid and targeted strategies for the automotive sector, more active support of agencies, universities and research institutes, more sophisticated demand conditions, and relatively more interaction (especially knowledge transfer) among agents.

- The so-called traditional (or low-tech) sectors may change over time quite drastically, and become increasingly knowledge-intensive and innovative. Salmon farming in Chile.

Michiko Iizuka, in "'Low-tech" industry: a new path for development? The case of the salmon farming industry in Chile', challenges the view that the 'low-tech' sectors - such as food and other natural-resource-based industries - are not dynamic or innovative enough to be the path to development and can only be regarded as a transitional phase to 'high-tech' sectors, especially in manufacturing. The chapter clearly shows that the so-called low-tech sectors can be innovative, and have undergone a major transformation that requires advanced capabilities - in particular, of combining existing technological, organizational and market knowledge from different technological domains. In these sectors the innovation process involves wide networks extending beyond national boundaries in order to encourage dynamic interactions in aligning the interests of agents, which subsequently redefine the sectoral boundaries. As an example of a case of transformation of "low-tech sectors", the Chilean salmon farming industry has shown successful development and reached world leadership in a premium natural-resource-based product. Here, this sector evolved over time by successfully using and combining advanced knowledge. The majority of firms engaged in cumulative and architectural innovation owing to the structural changes that took place in the sector. This made them interdependent 
on one another and forced them to perform as a cluster. Some key institutions shaped the agents and interactions among them. In particular an intermediate institution - the Association of the Salmon Industry - expanded its network to broaden its knowledge base so as to enhance negotiating power at the sectoral level.

- Vertical interdependencies and local demand may impair the full development of a sector. Machine tools in Korea.

Yoon-Zi Kim and Keun Lee, in 'Making a technological catchup in the capital goods industry: barriers and opportunities in the Korean case', discuss the role of interdependencies and demand in a key capital good industry such as machine tools. The point of the chapter is that growth and catch-up are difficult in capital goods industries usually characterized by small or middle-sized companies, even in countries with a high growth rate such as Korea. This is so because the vertical interaction and exchange of knowledge between advanced final producers and customers' firms are very important and may play against the development of the sector. The reason is that small firms in the capital goods industry are usually specialized suppliers to big final goods assembly firms in the consumer goods industry or other industries. Local client firms are reluctant to use locally made capital goods owing to their poor quality and low precision levels, so that dynamic processes of learning and capability formation by local capital goods producers cannot be set in motion. In addition, two other reasons may be present. First, while a successful catch-up first requires the ability to produce goods of better quality and lower prices than those produced by incumbent firms from advanced countries, incumbent foreign firms often react by charging predatory prices upon possible local development of capital goods by latecomers. In addition, if the catch-up firms overcome this barrier, then the next strategy used by incumbent firms is to charge latecomers with legal actions for patent violations. Despite these difficulties, the Korean economy has achieved a slow but gradual catch-up in the capital goods industry. The chapter attributes such incremental achievements to several factors, including the strenuous efforts of the government to support joint companies with a foreign partner, the creation of a certification of credibility by the government regarding the quality of the product $R \& D$ support, the profiting from the possibility of catching up given by the introduction and adoption of IT or digital technologies in machine tools, and the focus on niche markets in general-purpose machine tools and emerging economies in which limited interaction between producers and users is required. 
- Sectoral systems of innovation are embedded in the national system of innovation, and their evolution is both nurtured and hampered by the government. ICT in Taiwan.

Ting-Lin Lee, in her chapter "From "nuts and bolts" to "bits and bytes": the evolution of Taiwan ICT in a global knowledge-based economy', traces the evolution of the ICT industry in Taiwan. The ICT sectoral system was composed of two dominant agents, the government and foreign companies. However, the sectoral system of innovation of the Taiwanese semiconductor industry is largely shaped by two government research institutes, namely the Industrial Technology Research Institute (ITRI) and the Institute for Information Industry (III). The ITRI was established in 1973 by the Ministry of Economic Affairs (MoEA) as a national laboratory with the responsibility of developing technical capabilities for high-tech industries that the government had marked as strategic for Taiwan's development. As the ITRI undertook applied research, it accelerated industrial development by working closely with the private sector to ensure technology transfer from developed nations to domestic industries. With sponsorships from the MoEA, the ITRI conducted research that was shared with private firms. Also, the Institute conducted specific research for individual firms on a contract basis and formed R\&D collaborations to update Taiwanese firms on best practices from technologies around the globe. Equally, since 1979, the III has been a key technology contributor to Taiwan's ICT industry. Its founding and continuing mission has been to increase Taiwan's global competitiveness through the development of its IT infrastructure and industry. In order to support leading-edge research and speed up the pace of innovative breakthroughs, Taiwan has established a series of opentype national laboratories. The Taiwanese government has also promoted cooperation between industries and universities in recent years. Despite the significant role of government in the creation and nurturing of the semiconductor industry, the government realized that real prosperity is created by the private sector and so promoted a good balance of competition and collaboration among private firms to increase the competitiveness and productivity of the cluster. Also, financial organizations, universities and supporting industries contributed meaningfully to the development of the ICT industry. Taiwan's "miraculous growth" shows that government can play a leading role in the development of a specific sector but it must understand its role and should not overstep its boundaries to hinder other agents from playing their roles effectively. 
- Creating and nurturing sectoral systems of innovation in new technology-based industries in the rural areas of the developing world can be both difficult and complex. Biofuels in Tanzania.

This is the main message of the chapter 'Prospects for Jatropha biofuels in Tanzania: an analysis with strategic niche management' by Janske van Eijck and Henny Romijn. The high petroleum prices have forced the search for more renewable forms of energy. One such alternative source of diesel is from a plant called Jatropha. It will help meet the world's demand for fuel, without crowding out the world's supply of food, and it will regenerate dry and denuded soils and create jobs for impoverished farmers. Tanzania is one among a few developing countries that is cultivating Jatropha and then extracting bio-diesel out of it. In this context the authors raise the following questions. To what extent does Tanzania have the potential to develop Jatropha-based energy supply sources, and to what extent could these successfully substitute for fossil-based energy supplies? What has been its progress in that direction? And what are the major obstacles in this respect? These questions are then answered by mapping out the emerging national innovation system for Jatropha biofuels. The authors do this with an approach called strategic niche management (SNM), which is rooted in evolutionary economics. SNM has been designed specifically to study the introduction of radically new technologies in society that promise to contribute to more sustainable development patterns. Essentially, SNM conceptualizes the introduction of such technologies as the start of a broad and long-term transition process, in which widely used technologies with unsustainable characteristics are gradually replaced by new, cleaner technologies. SNM posits that this process encompasses a coevolution of technology and societal factors such as culture, institutions, consumption patterns and preferences, economic regulation, and political governance systems. The main conclusion of this chapter is that the innovation system for Jatropha biofuels in Tanzania is still in its infancy, and that its future is far from being clear. Despite the favourable constellation of many contextual 'landscape' factors, there remain prominent barriers within Tanzania's existing energy regime and agricultural regime. These include structural, infrastructural and logistical problems; technical skill and knowledge gaps; a limited local research infrastructure; the vested interests of powerful actors in the extant energy regime; cultural barriers associated with traditional uses of Jatropha; psychological obstacles emanating from known poisonous qualities of the crop; and a considerable price disadvantage for Jatropha oil except in remote locations. 


\section{SOME CONCLUSIONS}

Some conclusions on examining industries in a sectoral perspective in developing countries and on the public policy of support for innovation emerge from this book:

a. Understanding the specificities of the relevant sectoral systems is fundamental in order to identify the sources of innovation and development. This book has pointed to factors such as the knowledge base underpinning innovative and production activities in a sector, the vertical and horizontal interdependencies across sectors, the various actors involved in innovative and production activities, the networks that they form, the characteristics of demand and the relevant institutions. In a dynamic fashion, this requires also the identification of the specific coevolutionary process in which the sector is involved. Most chapters in this book clearly illustrate this point.

b. The awareness of the key differences existing across sectoral systems allows an understanding of why some factors affect innovation in some sectors and not in others and why some policies have a big impact in some sectors and a weak one in others. Again, most chapters in this book provide good examples.

c. The separation of research from development and production capabilities can be very harmful for innovation and development. The strong separation of research capabilities from production capabilities may lead to companies without any competence in production on one hand or to companies that rely too much on external research but do not have any internal capabilities on the other. As Chapter 2 shows, the two have to be integrated for successful innovation.

d. The type of networks that emerge in a sector is strongly associated with the specific knowledge base of that sector. Simply associating public knowledge with decentralized networks and private knowledge with hierarchical networks is too simplistic a statement. As Chapter 3 shows, an understanding of the type of knowledge involved is necessary for an understanding of why networks of certain types are present in the development of a sector.

e. The formation of networks and knowledge systems in developing countries may require complex alignment in a multi-level governance structure, including multinational corporation networks and domestic networks. As shown in Chapters 3 and 6, multinational companies may play a fundamental role in the accumulation of technological capabilities in new technologies, but their integration with existing networks and the diffusion of knowledge into existing social 
structures are not a homogeneous process. Specific institutional frameworks may allow for organizational learning and the decentralized interaction between stakeholders with very different interests.

f. In knowledge-intensive sectors, skills and human capital formation are particularly relevant for growth, as Chapter 5 shows.

g. A vibrant entrepreneurship and intense spin-offs are extremely important for innovation in sectors characterized by small and medium enterprises. As Chapter 5 illustrates, intense dynamic clustering is the result of these processes.

h. Public policy has to pay attention to the positive feedbacks but also to the blocking role that links and interdependencies between different sectors have on innovation and development. While these interdependencies often work in a positive way owing to local user-producer interactions, at other times the toughness of international competition at the final product level may block the development of an indigenous advanced capital goods industry because local final producers may decide to import advanced equipment in order to be internationally competitive, as Chapter 9 shows.

i. Traditional sectors are not necessarily low-tech or do not necessarily have low knowledge intensity; often they are innovative and they increasingly require the use and integration of advanced and differentiated knowledge. As Chapter 8 illustrates, some of these sectors have been radically transformed recently, are now highly knowledge-intensive and drive development.

j. Key institutions such as industrial associations may play a key role in coordination and networking mechanisms. The salmon farming case in Chapter 8 is a clear example. Chapter 4's pulp and paper story is still another example.

k. Depending on the instruments, timing and sectoral context, government can play the role of both a facilitator and an obstacle to the creation of a sectoral system of innovation. The former comes out of the analysis by Chapter 10's study of the Taiwanese ICT industry, and the latter follows very clearly from Chapter 11.

\section{REFERENCES}

Andersen, B., Metcalfe, J.S. and Tether, B.S. (2002), "Distributed innovation systems and instituted economic processes", Working Paper ESSY (http://www. cespri.unibocconi.it/essy/wp/metcalfeetal.pdf).

Arthur, B. (1989), "Competing technologies, increasing returns and lock-ins by historical events”, Economic Journal 99(394), pp. 116-131. 
Callon, M. (1992), "The dynamics of techno-economic networks", in Coombs, A.R.R., Saviotti, P. and Walsh V. (eds), Technological Change and Company Strategies: Economic and Sociological Perspectives, Academic Press, London.

Carlsson, B. and Stankiewitz, R. (1995), "On the nature, function and composition of technological systems", in Carlsson, B. (ed.), Technological Systems and Economic Performance: The Case of Factory Automation, Kluwer Academic Publishers, Dordrecht.

Cohen, W. and Levinthal, D. (1989), "Innovation and learning: the two faces of R\&D”, Economic Journal 99(397), pp. 569-596.

Cooke, P., Urange, M.G. and Extebarria, G. (1997), "Regional innovation systems: institutional and organizational dimensions", Research Policy 26, pp. 475-491.

Dahmen, E. (1989), "Development blocks in industrial economics", in B. Carlsson (ed.), Industrial Dynamics, Kluwer Academic Publishers, Dordrecht.

David, P. (1985), Clio and the economics of QWERTY, American Economic Review 75(2), pp. 332-337.

Dosi, G. (1988), "Sources, procedures and microeconomic effects of innovation", Journal of Economic Literature 26(3), pp. 1120-1171.

Dosi, G. (1997), "Opportunities, incentives and the collective patterns of technological change”, Economic Journal 107(444), pp. 1530-1547.

Dosi, G. and Malerba, F. (1996), Organization and Strategy in the Evolution of the Enterprise, Macmillan, London.

Dosi, G., Nelson, R.R. and Winter, S.G. (2000), The Nature and Dynamics of Organizational Capabilities, Oxford University Press, New York.

Edquist, C. (ed.) (1997), Systems of Innovation: Technologies, Institutions and Organisations, Frances Pinter, London.

Freeman, C. (1982), The Economics of Industrial Innovation, Frances Pinter, London.

Freeman, C. (1987), Technology Policy and Economic Performance: Lessons from Japan, Frances Pinter, London.

Hughes, T.P. (1987), "The evolution of large technological systems", in Bijker, W.E., Hughes, T.P. and Pinch, T.J.(ed.), The Social Construction of Technological Systems: New Directions in the Sociology and History of Technology, MIT Press, Cambridge, MA.

Klepper, S. (1996), "Entry, exit, growth and innovation over the product life cycle", American Economic Review 86(3), pp. 562-583.

Levin, R.C., Klevorick, A.K., Nelson, R.R. and Winter, S.G.(1987), “Appropriating the returns from industrial R\&D”, Brookings Papers on Economic Activity 3, pp. 783-831.

Lundvall, B.A. (1993), National Systems of Innovation, Frances Pinter, London.

Malerba, F. (2002), "Sectoral systems of innovation and production", Research Policy 31(2), pp. 247-264.

Malerba, F. (2004), Sectoral Systems of Innovation: Concepts, Issues and Analyses of Six Major Sectors in Europe, Cambridge University Press, Cambridge.

Malerba, F. and Orsenigo, L. (2000), "Knowledge, innovative activities and industry evolution", Industrial and Corporate Change 9(2), pp. 289-314.

Metcalfe, S. (1998), Evolutionary Economics and Creative Destruction, Routledge, London.

Nelson, R.R. (1993), National Innovation Systems: A Comparative Study, Oxford University Press, Oxford. 
Nelson, R.R. (1994), "The co-evolution of technology, industrial structure and supporting institutions", Industrial and Corporate Change 3(1), pp. 47-64.

Nelson, R.R. (1995), "Recent evolutionary theorizing about economic change", Journal of Economic Literature 33(1), pp. 48-90.

Nelson, R.R. and Rosenberg, N. (1993), "Technical innovation and national systems", in Nelson, R.R. (ed.), National Innovation Systems, Oxford University Press, Oxford.

Nelson, R.R. and Winter, S.G. (1982), An Evolutionary Theory of Economic Change, Belknap Press of Harvard University Press, Cambridge, MA.

Rosenberg, N. (1982), Inside the Black Box, Cambridge University Press, Cambridge.

Teece, D. and Pisano, G. (1994), "The dynamic capabilities of firms: an introduction", Industrial and Corporate Change 3(3), pp. 537-556. 